\title{
Generalistik: Bundesrat stimmt Gesetz zu
}

\section{Änderungen mit Ausbildungsjahrgang 2020 geplant}

") Der Bundesrat hat am 7. Juli dem Gesetz zur Reform der Pflegeberufe zugestimmt. Im Bundestag gab es schon vor einigen Wochen grünes Licht. Der Weg für den Kompromiss zur generalistischen Pflegeausbildung ist damit frei. In Kraft treten wird die Regelung stufenweise. Der erste Ausbildungsjahrgang soll 2020 beginnen. Das teilte das Gesundheitsministerium mit. Die wichtigsten Änderungen:

- Die bisher im Altenpflegegesetz und Krankenpflegegesetz getrennt geregelten Pflegeausbildungen werden im neuen Pflegeberufegesetz zusammengeführt.

- Alle Auszubildenden erhalten zwei Jahre lang eine gemeinsame Ausbildung. Wer die generalistische Ausbildung im dritten Jahr fortsetzt, er- wirbt den Abschluss zur Pflegefachfrau oder zum Pflegefachmann.

- Auszubildende, die ihren Schwerpunkt in der Pflege alter Menschen oder der Versorgung von Kindern und Jugendlichen sehen, können für das dritte Ausbildungsjahr statt des generalistischen Berufsabschlusses einen gesonderten Abschluss in der Altenpflege oder Gesundheits- und Kinderkrankenpflege erwerben.

- Sechs Jahre nach Beginn der neuen Ausbildung soll überprüft werden, ob für diese gesonderten Abschlüsse weiterhin Bedarf besteht.

-. Das Schulgeld wird grundsätzlich abgeschafft.

Am jetzt verabschiedeten Gesetz gab es in der Vergangenheit immer wieder Kritik. So hatte der Deutsche Berufs- verband für Pflegeberufe (DBfK) bemängelt: „Die jetzt verabschiedete Reform bleibt deutlich hinter dem ursprünglichen Gesetzentwurf zurück." Aus Sicht des Verbands trage der Kompromiss nur den Interessen einer kleinen Minderheit Rechnung. Als „verpasste Chance“ hatte Markus Mai, Präsident der rheinland-pfälzischen Landespflegekammer, die Kompromisslösung zur künftigen pflegerischen Ausbildung bezeichnet. Aber immerhin bedeute das neue „Pflegeberufegesetz" den ersten Schritt auf dem Weg zu einer generalistischen Pflegeausbildung.

\section{www.bundesgesundheitsministeri-} um.de

\section{Hier steht eine Anzeige.}

\section{黑 Springer}

